\title{
BMJ
}

\section{Comparison of different strategies in prenatal screening for Down's syndrome: cost effectiveness analysis of computer simulation}

\begin{abstract}
Jean Gekas, chief of prenatal diagnosis unit, consultant in medical genetic, and professor, ${ }^{1}$ Geneviève Gagné, research assistant, ${ }^{2}$ Emmanuel Bujold, consultant obstetrician and professor, ${ }^{3}$ Daniel Douillard, research assistant, ${ }^{2}$ Jean-Claude Forest, chief of medical biochemistry service, director of CHUQ medical research centre, and professor, ${ }^{4}$ Daniel Reinharz, professor, ${ }^{2}$ François Rousseau, professor ${ }^{4}$
\end{abstract}

${ }^{1}$ Centre de recherche du CHUQ Service de Génétique Médicale, Unité de Diagnostic Prénatal, Faculté de Médecine, Université Laval, Québec city, Québec, Canada

${ }^{2}$ Centre de recherche du CHUQ, Département de médecine sociale et préventive, Faculté de Médecine, Université Laval, Cité universitaire, Québec city

${ }^{3}$ Centre de recherche du CHUQ, Unité de Diagnostic Prénatal, Département d'ObstétriqueGynécologie, Faculté de

Médecine, Université Laval, Québec city

${ }^{4}$ Centre de recherche du CHUQ, Département de biologie

médicale, Faculté de Médecine

Université Laval, The

CanGèneTest research

consortium on genetic laboratory services, Québec city

Correspondence to: J Gekas, Centre Hospitalier de l'Université Laval (CHUL), 2705, boul. Laurier, bureau RC-9300, Sainte-Foy, Québec city, G1V 4G2, Québec, Canada jean.gekas@mail.chuq.qc.ca

Cite this as: $B M J$ 2009;338:b138 doi:10.1136/bmi.b138

Data sources The computer simulation was populated

Results The contingent screening strategy dominated all

\section{ABSTRACT}

Objectives To assess and compare the cost effectiveness of three different strategies for prenatal screening for Down's syndrome (integrated test, sequential screening, and contingent screenings) and to determine the most useful cut-off values for risk.

Design Computer simulations to study integrated, sequential, and contingent screening strategies with various cut-offs leading to 19 potential screening algorithms. with data from the Serum Urine and Ultrasound Screening Study (SURUSS), real unit costs for healthcare interventions, and a population of 110948 pregnancies from the province of Québec for the year 2001.

Main outcome measures Cost effectiveness ratios, incremental cost effectiveness ratios, and screening options' outcomes. other screening options: it had the best cost effectiveness ratio (\$C26833 per case of Down's syndrome) with fewer procedure related euploid miscarriages and unnecessary terminations (respectively, 6 and 16 per 100000 pregnancies). It also outperformed serum screening at the second trimester. In terms of the incremental cost effectiveness ratio, contingent screening was still dominant: compared with screening based on maternal age alone, the savings were \$C30 963 per additional birth with Down's syndrome averted. Contingent screening was the only screening strategy that offered early reassurance to the majority of women (77.81\%) in first trimester and minimised costs by limiting retesting during the second trimester (21.05\%). For the contingent and sequential screening strategies, the choice of cut-off value for risk in the first trimester test significantly affected the cost effectiveness ratios (respectively, from \$C26833 to \$C37 260 and from \$C35 215 to \$C45 314 per case of Down's syndrome), the number of procedure related euploid miscarriages (from 6 to 46 and from 6 to 45 per 100000 pregnancies), and the number of unnecessary terminations (from 16 to 26 and from 16 to 25 per 100000 pregnancies).

Conclusions Contingent screening, with a first trimester cut-off value for high risk of 1 in 9 , is the preferred option for prenatal screening of women for pregnancies affected by Down's syndrome.

\section{INTRODUCTION}

In the past 10-15 years, major advances have been made in prenatal screening for Down's syndrome, ${ }^{12}$ the foremost known genetic cause of mental retardation. ${ }^{3}$ It has been suggested that maternal age alone as a screening strategy should be abandoned, ${ }^{4}$ but there is still no consensus on the most cost effective alternative, and thus no national strategy exists in the United States or Canada. ${ }^{56}$

New strategies that allow a relatively high detection rate combine analyses from first and second trimesters of pregnancy. ${ }^{78}$ Different approaches have been proposed $^{679}$ such as

- The integrated test, in which the results from first trimester screening tests are not analysed until the results from second trimester tests are evaluated, when both sets are assessed together ${ }^{1}$

- Sequential screening, in which first trimester screening results determine whether second trimester testing is indicated: women with a positive first trimester result are offered invasive testing (chorionic villous sampling), whereas those with a negative result are offered another serum test $\mathrm{t}^{10}$

- Contingent screening, in which the first trimester screening results are used to categorise women as high, intermediate, or low risk. ${ }^{11}$ High risk women are offered early diagnosis (chorionic villous sampling), low risk women are reassured and do not undergo second trimester testing, and intermediate risk women are offered second trimester testing. The cut-off values between the risk categories vary depending on how the groups are defined. 
Published evaluations of screening programmes for Down's syndrome have primarily focused on the detection rates of the different strategies used. ${ }^{6}$ Although the detection rate is important for individuals, the cost effectiveness ratio and similar end points of screening strategies are needed for the development of optimal public health strategies. ${ }^{6}$ In that respect, only contradictory and limited data exist on the three above methods of combining first and second trimester tests. ${ }^{69}$ Using a decision analysis model based on data from the First and Second Trimester Evaluation of Risk (FASTER) trial, ${ }^{12}$ Ball et al reported that contingent screening dominated (lower costs with better outcomes) the integrated test. ${ }^{6}$ In contrast, Wald et al-summarising the modelling of integrated, sequential, and contingent screening strategies from data derived from the Serum Urine and Ultrasound Screening Study (SURUSS) ${ }^{13}$ - concluded that integrated screening had the best screening performance. ${ }^{9}$ However, recent reports underline the insufficiency of data on these three screening strategies. ${ }^{5914}$ For sequential and contingent testing, there is no consensus on cutoff levels, resulting in variations in performance measured. ${ }^{8}$ A workshop of experts convened by the National Institutes of Health concluded that the contingent screening strategy needed further study before its widespread implementation could be recommended. ${ }^{8}$

Given the countless screening strategies available, ${ }^{715}$ regional differences in local resources, ${ }^{5}{ }^{16}$ and the costs

\section{Definitions of screening procedures}

\section{Integrated test}

Measurements performed at different times of pregnancy are integrated into a single test result. Unless otherwise qualified, it refers to the integration of nuchal translucency measurement (by ultrasound scan of the width of an area of translucency at the back of the fetal neck) and measurement of pregnancy associated plasma protein A (PAPP-A) in the first trimester with the quadruple test markers in the second trimester (measurement of maternal serum concentrations of a fetoprotein, unconjugated oestriol, free or total $\beta$ human chorionic gonadotrophin, and inhibin A) together with maternal age.

\section{Sequential screening}

First trimester tests are performed (nuchal translucency measurement and PAPP-A) and interpreted immediately. If the result is positive, the mother is offered a diagnostic test (chorionic villous sampling), but if it is not positive, second trimester serum markers (quadruple test markers) are measured and the results combined with the first trimester results to form an integrated test.

\section{Contingent screening}

First trimester tests (nuchal translucency measurement and PAPP-A) are used to categorise pregnant women as high, low, or intermediate risk. High risk women (positive result) are immediately offered a diagnostic test (chorionic villous sampling), low risk women (negative test result) receive no further screening, and intermediate risk women (lower risk positive result) undergo second trimester screening (quadruple test markers) for an integrated test to be done.

\section{Triple test}

Second trimester test based on the measurement of maternal serum $\alpha$ fetoprotein, unconjugated oestriol, and free or total $\beta$ human chorionic gonadotrophin, together with maternal age. of prospective clinical studies, ${ }^{17}$ no empirical study can be foreseen that would compare all options available for the three approaches to combining first and second trimester analyses. There are indeed too many possible combinations of tests, sequences, cut-off values, and schedules to be handled in a single study. Only computer simulations can compare all the options to identify the most cost effective. ${ }^{6917-19}$

In the current analysis, we performed computer simulations to compare 19 different screening options based on the three screening approaches (integrated test and sequential and contingent screenings) with various cut-off levels and using real data from the SURUSS trials. ${ }^{913}$ Our aims were to

- Analyse the cost effectiveness ratio of the different screening options from a public health perspective

- Compare their performance estimates for an overall $90 \%$ detection rate by evaluating seven other relevant end points that cover the main outcomes in prenatal screening for Down's syndrome $^{917}$ :

1) False positive rate that defines the number of scheduled amniocentesis procedures

2) Number of procedure related miscarriages of normal (euploid) fetuses

3) Number of live births with Down's syndrome

4) Number of unnecessary terminations

5) Proportion of pregnancies affected by

Down's syndrome that were screened by a first trimester test

6) Proportion of patients reassured early in gestation by first trimester testing

7) Proportion of continuing pregnancies that proceed to a second trimester test

- Compare the effects of eight different first trimester cut-off values in contingent and sequential screening strategies to determine the optimal value.

\section{MATERIAL AND METHODS}

\section{Screening strategies and tests}

The screening strategies considered were the integrated test, sequential screening, and contingent screening compared with maternal age alone ( $\geq 35$ years), which has been the standard since antenatal diagnosis guidelines for invasive testing were established in the US in the late $1970 \mathrm{~s},{ }^{20}$ and the triple test, which has been widely available in Europe and Canada since 1991. ${ }^{81621}$ The box gives further details of the screening strategies and the tests used.

Sequential and contingent screening strategies consist of a sequence of tests with many possible cut-off values for the risk of the fetus having Down's syndrome, but screening performance has been reported for only eight different cut-off points for first trimester tests ( 1 in 6, 1 in 9, 1 in 30, 1 in 58, 1 in 114,1 in 175,1 in 237, and 1 in 307). ${ }^{9}$ We compared 19 screening algorithms comprised possible screening scenarios resulting from the three screening 
strategies (integrated test and sequential and contingent screening), different cut-off values for contingent and sequential screenings, the triple test, and maternal age alone. For contingent screening, we also used a lower risk cut-off of 1 in 2000.

\section{Diagnostic tests}

The diagnostic procedures included in our simulation were conditional on the stage of pregnancy in accordance with best practice in prenatal care. Thus, amniocentesis was used for prenatal diagnosis only after second trimester screenings results, whereas women with a positive result at the first trimester screening were considered for transabdominal chorionic villous sampling for caryotyping. Timing of procedure-related euploid miscarriages is dependent on the test undergone. Our computer model also accounted for the performance characteristics of the diagnostic tests (amniocentesis and chorionic villous sampling).

Table 1| Input variables used in computer simulation of 19 different screening options in prenatal screening for Down's syndrome

\begin{tabular}{|c|c|c|}
\hline Input variables & Value & Data sources \\
\hline Costs of procedures & Costs $(\$ C)^{*}$ & \\
\hline Integrated test & 65.00 & \multirow{4}{*}{$\begin{array}{l}\left.\text { MSSS }(2005),{ }^{30}(2007)\right)^{31} \\
\text { RAMQ }(2007)^{33}\end{array}$} \\
\hline Sequential screening & 105.00 & \\
\hline Contingent screening & 55.00 & \\
\hline Triple test & 15.00 & \\
\hline Consulting with a genetic counsellor & 73.90 & RAMQ $(2007)^{33}$ \\
\hline Chorionic villous sampling & 876.00 & \multirow{2}{*}{$\begin{array}{l}\text { MSSS }(2005),{ }^{30}(2007),{ }^{31} \\
\text { RAMQ }(2005),,^{33}(2007)^{33}\end{array}$} \\
\hline Amniocentesis & 500.00 & \\
\hline Termination of pregnancy & 1357.33 & MSSS $(2003)^{29}$ \\
\hline Screening tests with $90 \%$ detection rate & False positive rate (\%) & \\
\hline Integrated test (1/245 cut-off value) & 2.60 & Wald et al $(2003)^{13}$ \\
\hline \multicolumn{2}{|l|}{$\begin{array}{l}\text { Sequential screening, cut-off values for first } \\
\text { trimester test: }\end{array}$} & \multirow{9}{*}{ Wald et al (2006) ${ }^{9}$} \\
\hline $1 / 6$ & 2.11 & \\
\hline $1 / 9$ & 2.12 & \\
\hline $1 / 30$ & 2.25 & \\
\hline $1 / 58$ & 2.46 & \\
\hline $1 / 114$ & 2.97 & \\
\hline $1 / 175$ & 3.65 & \\
\hline $1 / 237$ & 4.42 & \\
\hline $1 / 307$ & 5.23 & \\
\hline \multicolumn{2}{|l|}{$\begin{array}{l}\text { Contingent screening, cut-off values for first } \\
\text { trimester test: }\end{array}$} & \multirow{9}{*}{ Wald et al (2006) } \\
\hline $1 / 6$ & 2.29 & \\
\hline $1 / 9$ & 2.29 & \\
\hline $1 / 30$ & 2.42 & \\
\hline $1 / 58$ & 2.62 & \\
\hline $1 / 114$ & 3.11 & \\
\hline $1 / 175$ & 3.74 & \\
\hline $1 / 237$ & 4.47 & \\
\hline $1 / 307$ & 5.27 & \\
\hline Triple test (1/690 cut-off value) & 14.70 & Wald et al $(2003)^{13}$ \\
\hline
\end{tabular}

${ }^{*}$ Canadian dollars (\$C), exchange rate in 2007: \$C1.0748=\$US1.00.

\section{Decision model}

We developed a computer program in C11 language that simulates all 19 screening scenarios. The program was devised to

- Generate a virtual population with characteristics related to the prevalence and clinical course of pregnancies affected by Down's syndrome and unaffected pregnancies, as well as maternal age distribution

- Construct the various screening algorithms for the screening and diagnosis options for Down's syndrome

- Simulate screening of this virtual population with each algorithm and measure pregnancy outcomes

- Establish the direct healthcare costs of each screening option using costs of procedures and of complications provided by the Ministry of Health.

Figure 1 shows a simplified version of the decision model. The model includes several possible outcomes of screening and diagnostic testing decisions, including birth of a baby with no chromosomal disorder, birth of a baby with Down's syndrome, miscarriage, elective abortion after positive test results, and whether a pregnancy loss occurs after a diagnostic test.

\section{Data used in analysis}

Table 1 lists all the input variables and their data sources. Table 2 shows the demographic characteristics of the virtual population used in our computer simulation and the most critical assumptions. Our virtual population of 110948 pregnancies corresponded to all pregnancies in Québec province in year $2001^{2223}$ with the same maternal age distribution. This population was of mixed origins, mainly white, and table 2 contains details of maternal ages.

\section{Probabilities}

Pregnancies affected by Down's syndrome and risk of miscarriage-We estimated the risk of a pregnancy being affected by Down's syndrome by multiplying the specific odds by maternal age of having an affected live birth $^{2425}$ (corrected for the spontaneous miscarriage of fetuses with Down's syndrome ${ }^{2627}$ ) by the likelihood ratio (for a given set of marker values) obtained from the overlapping multivariate Gaussian distributions of marker levels in affected and unaffected pregnancies. ${ }^{9}$ If a woman chooses to undergo amniocentesis, she is at risk of a miscarriage before she has the test and either before or after the test results are given.

Test performance-We used the distribution of marker values in pregnancies affected by Down's syndrome and in unaffected pregnancies reported in the SURUSS trials to determine the parametric values (means, standard deviations, correlation coefficients, and truncation limits) ${ }^{9}{ }^{13} \mathrm{We}$ included rates of false positive and false negative test results in the calculations. 
Table 2 | Demographic characteristics of the population and the most critical assumptions used in computer simulation of 19 different screening options in prenatal screening for Down's syndrome

\begin{tabular}{|c|c|c|}
\hline Characteristics & Value & Data sources \\
\hline \multicolumn{3}{|l|}{ Population simulated } \\
\hline Total No of pregnant women & 110948 & MSSS $(2007)^{23}$ \\
\hline \multicolumn{3}{|l|}{$\begin{array}{l}\text { No of pregnancies affected by Down's } \\
\text { syndrome: }\end{array}$} \\
\hline At first trimester & 290 & \multirow{4}{*}{$\begin{array}{l}\text { AETMIS (2003), }{ }^{22} \text { Snijders (1999), } \\
\text { Morris et al (1999) })^{55}\end{array}$} \\
\hline At second trimester & 190 & \\
\hline At third trimester & 140 & \\
\hline At birth & 131 & \\
\hline \multicolumn{2}{|l|}{ No of women by age (years): } & \multirow{11}{*}{ MSSS $(2007)^{23}$} \\
\hline$<20$ & 9008 & \\
\hline $20-24$ & 24987 & \\
\hline $25-29$ & 33421 & \\
\hline $30-34$ & 27320 & \\
\hline $35-39$ & 13135 & \\
\hline $40-44$ & 2925 & \\
\hline$\geq 45$ & 157 & \\
\hline$\ll 35$ years old & 94735 & \\
\hline$\geq 35$ years old & 16213 & \\
\hline Mean maternal age (years) & 27 & \\
\hline \multicolumn{3}{|l|}{ Assumed probabilities (\%) } \\
\hline Consent to participate in prenatal screening & 70.0 & \\
\hline $\begin{array}{l}\text { Consent for amniocentesis or chorionic villous } \\
\text { sampling with screening positive }\end{array}$ & 90.0 & Forest et al (2004) ${ }^{28}$ \\
\hline Fetal loss from amniocentesis & 0.5 & \multirow{2}{*}{$\begin{array}{l}\text { AETMIS (2003), }{ }^{22} \text { Sundberg et al } \\
(1997),{ }^{56} \text { CETS }(1997)^{57}\end{array}$} \\
\hline Fetal loss from chorionic villous sampling & 1.6 & \\
\hline $\begin{array}{l}\text { Proportion who terminated pregnancy with } \\
\text { fetal Down's syndrome }\end{array}$ & 90.0 & Forest et al $(2004)^{28}$ \\
\hline
\end{tabular}

Other probabilities - Our simulation included the level of compliance previously estimated in the Québec population $^{28}$ - that is, the proportion of women who consent to participate in prenatal screening for Down's syndrome and to a diagnostic test after a positive screening result. We also included the chance that a woman will choose elective abortion after a positive diagnostic test. $^{28}$

\section{Costs}

In Canada, in accordance with the Canadian Health Care Act, all services considered as medically necessary are generally provided exclusively inside the public healthcare system and are free of charge. We considered only direct costs under the Ministry of Health and the Public Medical Assurance perspectives. Unit prices were averages for Quebec province calculated from government databases (financial and operative databank SIFO and APR-DRG). Costs for laboratory and imaging tests were from technical units for Quebec province. ${ }^{29-33}$ These unit prices include the costs of necessary support services (such as administration, security, cleaning, etc).$^{34}$ Items considered for costing comprised screening costs and medical services related to the following outcomes - birth, spontaneous miscarriage, elective abortion after positive test results, or pregnancy loss after a diagnostic test. Costs are expressed in Canadian dollars (\$C) at 2007 values (exchange rate: $\$ \mathrm{C} 1.0748=\$ \mathrm{US} 1.00$ ).

\section{Cost effectiveness analysis}

Our approach follows guidelines for cost effectiveness analysis in prenatal diagnosis. ${ }^{17}$ The analyses were run to evaluate global costs, cost effectiveness ratios (costs per case of Down's syndrome diagnosed), and incremental cost effectiveness ratios comparing all 19 screening options. Incremental cost effectiveness ratio was calculated by dividing the difference in cost between each screening strategy and screening based on maternal age only (amniocentesis for women aged $\geq 35$ years) by the difference in the number of cases of Down's syndrome detected by the two strategies. The incremental cost effectiveness ratio therefore represents the additional cost or savings per additional abnormality detected. All measured costs occurred within one year; and so there was no need to discount costs and effects over time. ${ }^{17}$

\section{Sensitivity analyses}

In order to test the robustness of our findings, we performed a series of simulations (univariate sensitivity analyses) in which we varied the major assumptions of the modelling with values proposed in the AETMIS report $^{22}$ and recalculated the cost effectiveness ratios. ${ }^{17}$ Apart from the values shown in tables 1 and 2, we also tested the effects of

- Rates of consent to participate in prenatal screening of $65 \%$ and $80 \%{ }^{22}$

- Rates of fetal loss from chorionic villous sampling of $0.5 \%, 1 \%$, and $2 \%$, and from amniocentesis of $1 \%$ and $1.5 \%{ }^{22}$

- The proportion of couples with a fetus with confirmed Down's syndrome who would undergo pregnancy termination, namely $70 \%$ and $80 \%$

- Varying the sensitivities and false positive rates of the screening strategies over the ranges achieved in the SURUSS trial. ${ }^{913}$

\section{Estimation of confidence intervals}

In order to generate $95 \%$ confidence intervals for our estimates of cost effectiveness ratios, we used the method of replications. ${ }^{35}$ This consisted of simulating each screening option 100 times on a virtual population of 110948 pregnancies $(100 \times 110948$ individuals $)$. It resulted in more than 11 million individuals being screened for computing the mean cost effectiveness ratios for each screening scenario.

\section{RESULTS}

\section{Cost effectiveness analysis}

Table 3 summarises the results of our cost effectiveness analysis. The most cost effective screening strategy seems to be contingent screening (cost effectiveness ratio \$C26833 per case of Down's syndrome with a high risk cut-off value of 1 in 30 ). These results were robust in sensitivity analyses: none of these different 


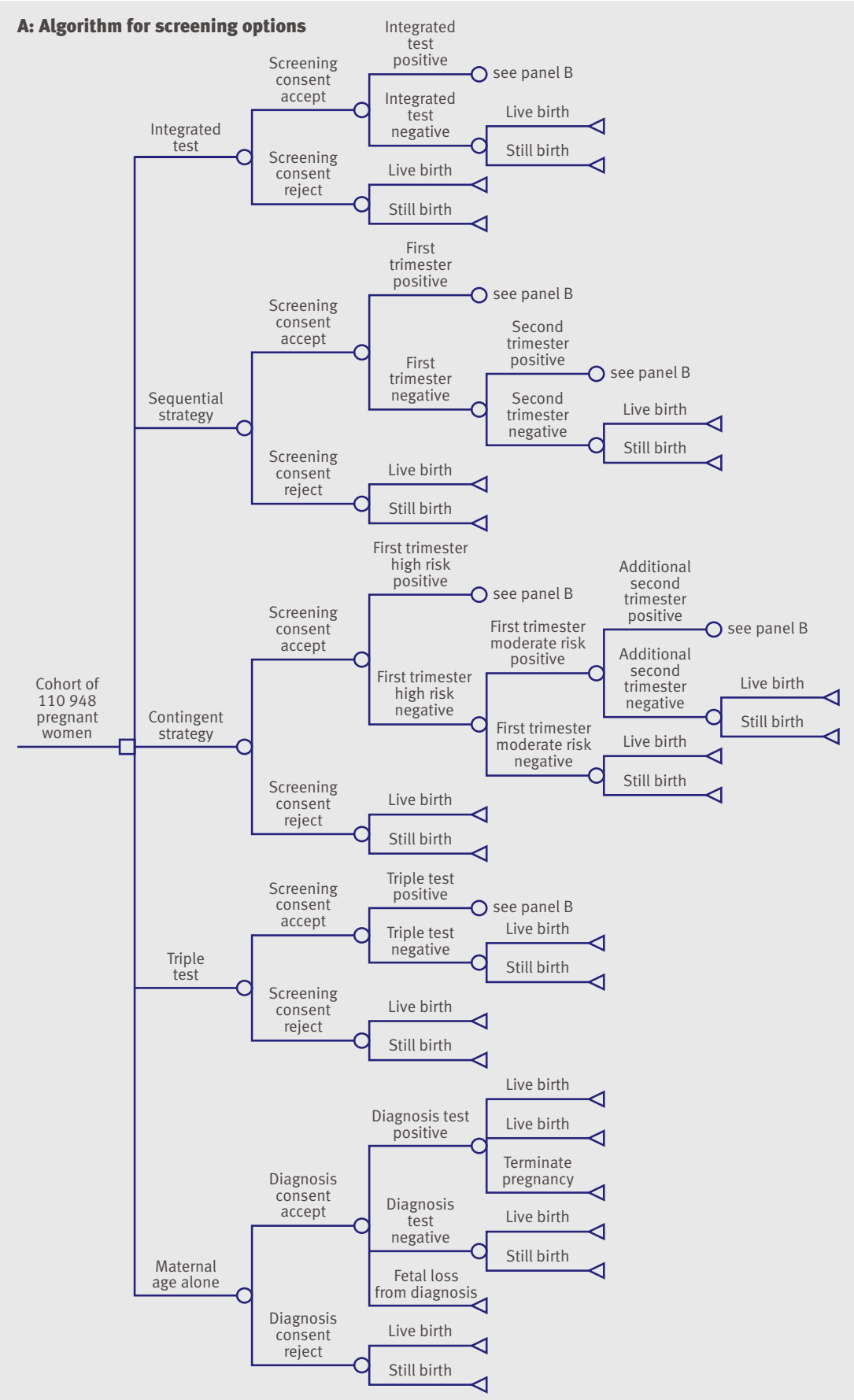

B: Algorithm for diagnosis procedure



Fig 1 | Simplified version of the decision model for screening options (panel A) and diagnosis procedure (panel B) used in computer simulation of prenatal screening strategies for Down's syndrome. Not shown, but included in the real model, is the possibility that miscarriage occurs before testing or after test results are known models yielded a different relative rank of the various screening scenarios analysed. Compared with the reference screening strategy (maternal age only), the incremental cost effectiveness ratio of contingent screening (with cut-off value of 1 in 6) is $-\$ C 30963$ per averted birth with Down's syndrome. The estimated costs per prevented birth with Down's syndrome were \$C35215 for sequential screening, \$C38 944 for integrated screening, and \$C43 809 for the triple test. Consequently, the contingent screening strategy seems to be most cost effective. As expected, amniocentesis based on advanced maternal age only is the least cost effective option, with a cost effectiveness ratio of \$C74 037 per case of Down's syndrome.

\section{Screening strategies outcomes}

Depending on the specific end points that are considered, different screening approaches may seem more appropriate. The most appropriate screening test for Down's syndrome should have the lowest false positive rate (to minimise the number of invasive procedures required and their related complications), the highest detection rate, and the best cost effectiveness ratio. ${ }^{16}$ The screening procedure (non-invasive screening and diagnostic technique) may also interfere with the number of live births with Down's syndrome. Figure 2 shows the effects of the different screening strategies on these major end points-false positive rate, number of procedure-related euploid miscarriages, and number of live births with Down's syndrome.

Early diagnosis of pregnancies affected by Down's syndrome may result in unnecessary terminations since some of the affected fetuses would be spontaneously aborted before term. ${ }^{9}$ Some studies have suggest that, in order to avoid this problem, women prefer a lower false positive rate, ${ }^{3637}$ but others suggest that women want early diagnosis. ${ }^{389}$ We evaluated the effect of the different screening strategies on this issue by calculating the number of unnecessary terminations, the proportion of pregnancies affected by Down's syndrome screened by a first trimester test, and the proportion of continuing pregnancies that proceed to a second trimester test (fig 3).

Contingent and sequential screening strategies produced similar results on the major outcomesrespectively, $1.43 \%$ and $1.55 \%$ for false positive results (fig 2), six procedure related euploid miscarriages each (fig 2), 16 unnecessary terminations each (fig 3), and $43.71 \%$ and $44.13 \%$ of affected pregnancies with a positive first trimester test (fig 3) (these results are those achieved with the most favourable cut-off value). However, contingent screening was unique in permitting $77.81 \%$ of patients to be reassured at the first trimester and $77.95 \%$ of women to avoid retesting in the second trimester (proportion of continuing pregnancies that proceed to a second trimester testing, fig 3). Indeed, contingent screening (whatever the cut-off value) allowed about $78 \%$ of women $(77.75 \%$ to $78.51 \%)$ to be reassured with a negative screening result early in gestation, which was obviously not 
possible integrated, sequential, or triple test screening strategies.

In the same manner, we found that integrated screening was associated with a low number of procedure related euploid miscarriages $(n=6$, fig 2$)$ and, in conjunction with the triple test, gave the best result for unnecessary terminations ( $\mathrm{n}=6$ for both, fig 3 ). Moreover, the integrated test's false positive rate is close to those achieved by sequential and contingent screening $(1.82 \%, 1.43 \%$, and $1.55 \%$ respectively, fig 2).

\section{Impact of cut-off values in first trimester screening} We simulated the use of different cut-off values for the risk of a fetus having Down's syndrome in the first trimester tests of the contingent and sequential screening strategies. For both contingent and sequential screening, these had significant effects on

- Cost effectiveness ratios (from \$C26 833 to \$C37 260 and from \$C35215 to \$C45 314 per case of Down's syndrome respectively, table 3 )

- False positive rate $(1.55 \%$ to $3.69 \%$ and $1.43 \%$ to $3.66 \%$, fig 2)

- Number of procedure related euploid miscarriages (6 to 46 and 6 to 45 , fig 2 )

- Number of unnecessary terminations (16 to 26 and 16 to 25 , fig 3 )

Table $3 \mid$ Cost effectiveness analysis of different screening options in prenatal screening for Down's syndrome*

\begin{tabular}{|c|c|c|c|c|}
\hline Screening options & $\begin{array}{l}\text { Global costs } \\
\text { (\$Cmillions) } †\end{array}$ & Effectiveness $\ddagger$ & $\begin{array}{l}\text { Cost effectiveness } \\
\text { ratio }\end{array}$ & $\begin{array}{l}\text { Incremental cost } \\
\text { effectiveness ratio }\end{array}$ \\
\hline $\begin{array}{l}\text { Amniocentesis for } \\
\text { women } \geq 35 \text { years old }\end{array}$ & 4.1549 & 56.12 & 74037 & 1.00 \\
\hline \multicolumn{5}{|l|}{$\begin{array}{l}\text { Contingent screening, } \\
\text { cut-off values for first } \\
\text { trimester test: }\end{array}$} \\
\hline $1 / 6$ & 2.7529 & 101.40 & 27149 & -30963 \\
\hline $1 / 9$ & 2.7630 & 102.48 & 26961 & -30025 \\
\hline $1 / 30$ & 2.8579 & 106.51 & 26833 & -25739 \\
\hline $1 / 58$ & 2.9960 & 108.67 & 27570 & -22054 \\
\hline $1 / 114$ & 3.2596 & 109.72 & 29708 & -16704 \\
\hline $1 / 175$ & 3.5509 & 111.69 & 31792 & -10871 \\
\hline $1 / 237$ & 3.8494 & 111.61 & 34490 & -5506 \\
\hline $1 / 307$ & 4.1999 & 112.72 & 37260 & 795 \\
\hline
\end{tabular}

Sequential screening,

cut-off values for first

trimester test:

\begin{tabular}{lllll}
\hline $1 / 6$ & 3.6265 & 100.88 & 35949 & -11805 \\
\hline $1 / 9$ & 3.6400 & 101.63 & 35816 & -11315 \\
\hline $1 / 30$ & 3.7440 & 106.32 & 35215 & -8185 \\
\hline $1 / 58$ & 3.8662 & 109.07 & 35447 & -5453 \\
\hline $1 / 114$ & 4.1326 & 108.78 & 37991 & -423 \\
\hline $1 / 175$ & 4.4416 & 112.37 & 39526 & 5096 \\
\hline $1 / 237$ & 4.7597 & 110.62 & 43027 & 11096 \\
\hline $1 / 307$ & 5.0960 & 112.46 & 45314 & 16704 \\
\hline Integrated test & 3.3944 & 87.16 & 38944 & -24502 \\
\hline Triple test & 3.8324 & 87.48 & 43809 & -10285 \\
\hline
\end{tabular}

*Values are per 100000 pregnancies in prenatal care for an overall $90 \%$ detection of cases of Down's syndrome. †Canadian dollars (\$C), exchange rate in 2007: \$C1.0748=\$US1.00.

$\ddagger$ No of cases of Down's syndrome detected by screening test.
- Proportion of affected pregnancies with a positive result from the first trimester test $(44.1 \%$ to $86.1 \%$ and $43.7 \%$ to $86.3 \%$, fig 3$)$.

\section{DISCUSSION}

\section{Limitations of study}

Our results are based on mathematical modelling and not on prospective observational data. However, we used empirical data and true healthcare costs as input parameters for the simulations. Given geographical limitations, resource differences between regions, and the many possible screening strategies for Down's syndrome, it is unlikely that a large scale, comprehensive, prospective, clinical trial could be organised across North America. Our approach was useful in allowing 19 different strategies to be assessed and compared simultaneously. ${ }^{1840-42}$

Our reported cost effectiveness ratios were based on Québec province's healthcare system and costs. However, given the robustness of our findings observed in the sensitivity analyses (in which we varied the values of the major assumptions of the modelling), our conclusions are likely to be applicable to other jurisdictions. The demographic characteristics of the population we simulated are similar to those of other Western countries. In particular, the mean maternal age and the proportion of women aged $\geq 35$ years were similar to those of the populations of the SURUSS and the FASTER trials, which represented women in the UK and US. ${ }^{12} 13$ The effect of the maternal age distribution on the detection rate of Down's syndrome is reported to be limited and unlikely to be large enough to influence screening policy decisions. ${ }^{43}$ Also, pregnancy outcomes are likely to be similar across different populations. With respect to healthcare costs, they could be estimated for other provinces by using other costs units in the simulation model.

Most improvements in overall cost effectiveness attained with a screening strategy are due to the reduction in live births with Down's syndrome. ${ }^{18}$ An important drawback of studies that incorporate the future costs of caring for a child with Down's syndrome into their cost effectiveness or cost utility analyses ${ }^{644}$ is that they do not incorporate commensurate benefits of having such a child. ${ }^{45}$ In accordance with previous reports, ${ }^{946-48}$ we decided not to consider the cost of caring for a child with Down's syndrome. However, computing the cost per case of Down's syndrome detected allows us to compare different screening strategies on a common ground.

Our study did not consider the logistical problems and costs of implementing a screening strategy that includes nuchal translucency measurement or chorionic villous sampling in North America. ${ }^{815}$ Neither technique is universally available throughout the US and Canada, ${ }^{1518}$ and the cost of establishing a screening programme with mandatory use of the techniques, including its administrative and technical challenges, is unknown. ${ }^{1550}$ Because of this, some have speculated that such a screening programme is not justifiable $\mathrm{e}^{15}$ or has serious implications for resource use. ${ }^{16}$ 
Cut-off values for contingent and sequential screening options

There is no consensus on what are the most appropriate cut-off values for high risk in the first trimester tests for contingent and sequential screening strategies, ${ }^{8}$ even though they could have a major effect on screening performance ${ }^{69}$ Our data show the impact of modulating the cut-off values and confirm that, for risk assessment to be successful, a careful choice of cut-off is required.

The first aim of using non-invasive screening is to reduce the number of procedure related euploid miscarriages. ${ }^{50}$ Our analysis suggests that first trimester cut-off values for high risk of 1 in 6 and 1 in 9 are most appropriate because they lead to the same number of procedure-related euploid miscarriages as occurs with the integrated test (which is considered the optimum screening option for limiting the procedure related euploid miscarriages $\left.{ }^{9}\right)$. With these cut-off values, contingent screening remains more cost effective than the integrated test and sequential screening. Our results are consistent with those of Wald et al, ${ }^{9}$ who reported
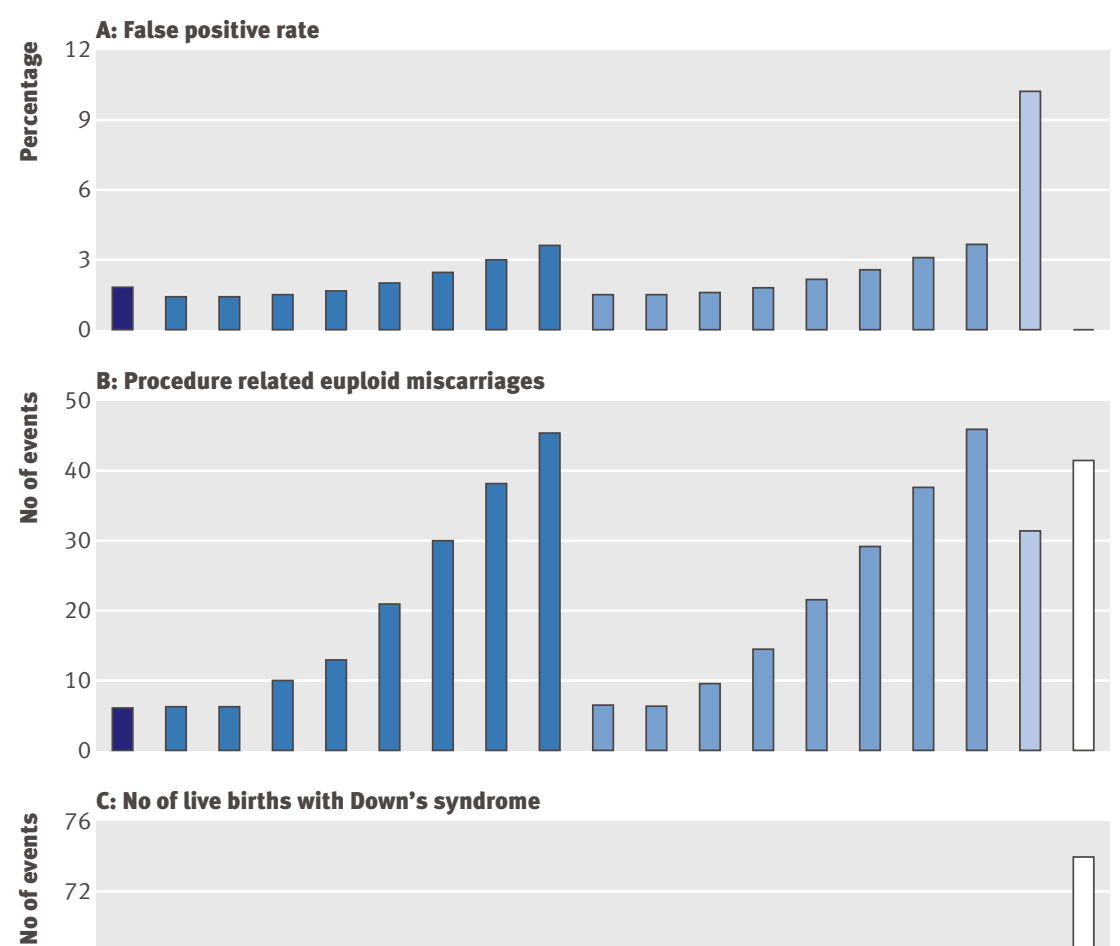

68

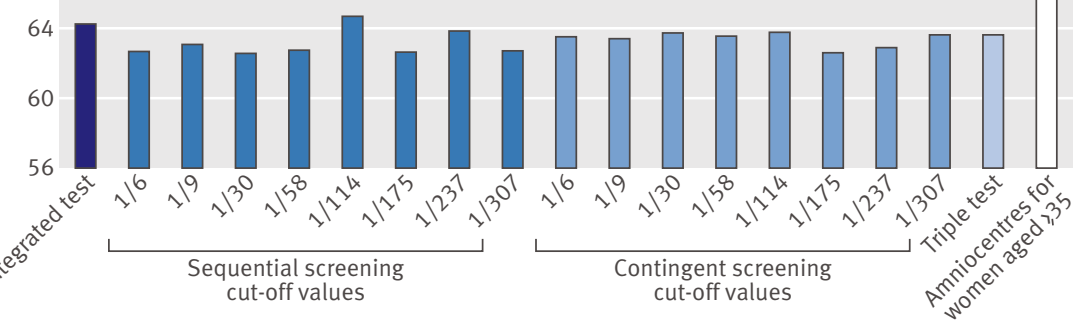

Fig 2 | Effects of different prenatal screening strategies for Down's syndrome on (A) rate of false positive results, (B) number of procedure related euploid miscarriages, and (C) number of live births with Down's syndrome (all values are per 100000 pregnancies) that, with a first trimester cut-off point for high risk of 1 in 30, the number of procedure-related euploid miscarriages was greater in contingent and sequential screening options than in the integrated test, and that contingent screening, but not sequential screening, was more cost effective than the integrated test. ${ }^{9}$

For contingent screening, the optimal cut-off value seems to be 1 in 9 cut-off with regard to cost effectiveness. The cut-off value of 1 in 30 showed the best cost effectiveness ratio, whereas the value of 1 in 6 produced the best incremental cost effectiveness ratio: hence, an in between value of 1 in 9 should achieve the best balance between these performance measures.

This value has important implications because the first trimester cut-off values traditionally used by healthcare professionals are much lower. Before the development of new screening strategies that combine first and second trimester tests, ${ }^{78}$ only the combined test (first trimester measurement of nuchal translucency, pregnancy associated plasma protein $\mathrm{A}$, and $\beta$ human chorionic gonadotrophin) used a first trimester cut-off value. The value for this test, which has become the de facto standard of care in the UK and may spread in North America, ${ }^{651}$ is 1 in 670 for obtaining a $90 \%$ detection rate. ${ }^{13}$ With strategies that combine first and second trimester tests, ${ }^{78}$ healthcare workers would have to be prepared (and trained) for the use of the much higher level of 1 in 9, and appropriate information would be needed for patients. Risk levels are often misunderstood by patients, ${ }^{52}$ and it may be difficult to refuse a diagnostic test at first trimester for an anxious woman with a calculated risk close to the 1 in 9 cut-off point because some women want an early diagnosis. ${ }^{3839}$ However, the use of inappropriate cutoff values in the first trimester may produce an excess in iatrogenic losses and costs.

\section{Different screening strategies \\ Contingent screening}

Our results confirm previous reports ${ }^{6}$ that contingent screening dominates all other options:

- Best cost effectiveness for achieving a lower overall false positive rate leading to better outcomes

- Fewer procedure related euploid miscarriages and unnecessary terminations

- Lowest cost per case of Down's syndrome detected

- Best incremental cost effectiveness ratio.

Contingent screening also offers early testing to those most likely to have an affected pregnancy (as does sequential screening), and it is the only option that allows the majority of women to be reassured early in gestation. Furthermore, it minimises costs by limiting retesting at the second trimester. Avoiding such repeat blood tests is a major reduction in unneeded clinic visits and their attendant costs. In our model, starting with 110948 pregnancies, the removal of about 86484 second clinic visits, blood draws, and reagent costs, results in major cost savings. Additionally, savings to 

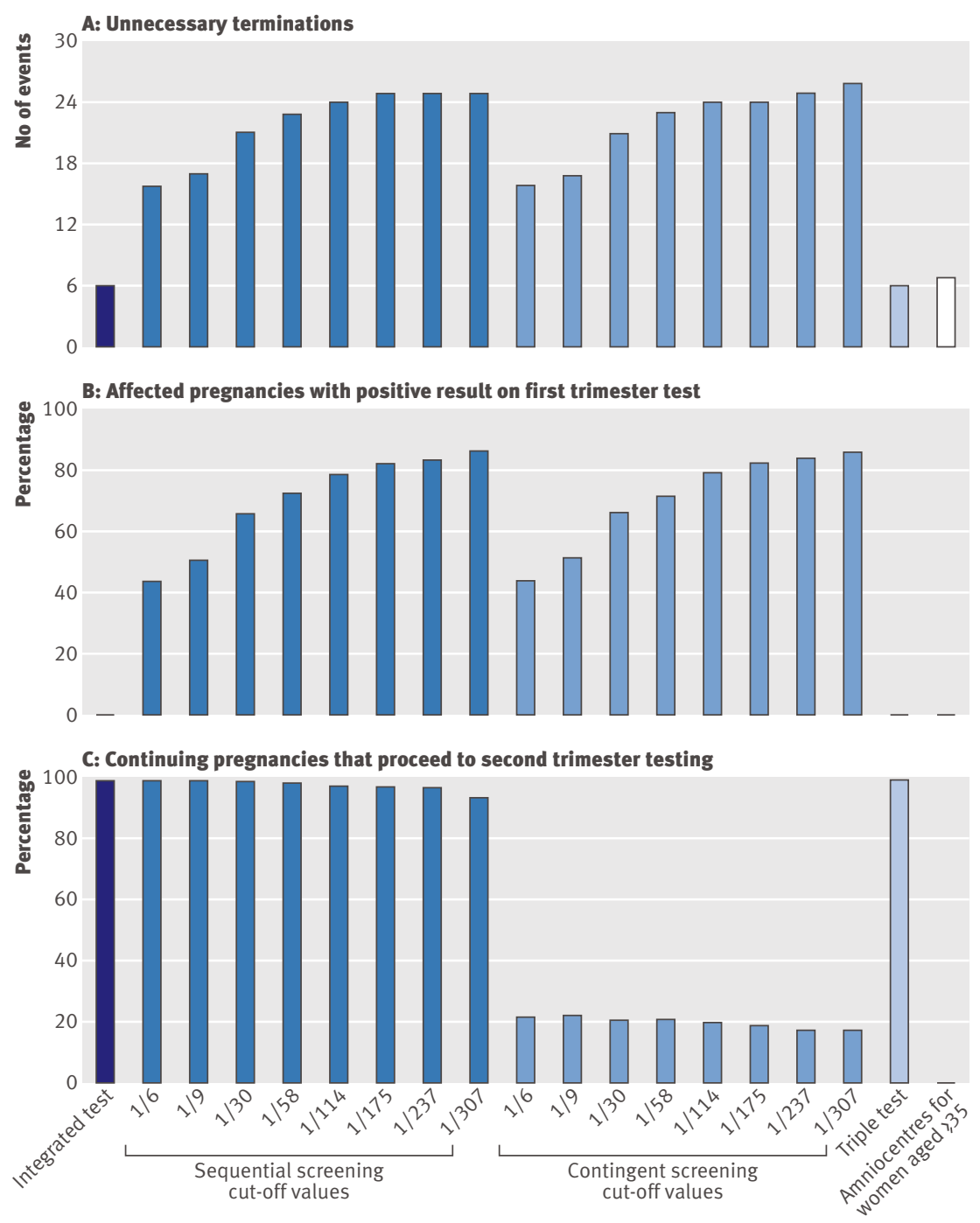

Fig 3 Effects of different prenatal screening strategies for Down's syndrome on (A) number of unnecessary terminations, (B) proportion of pregnancies affected by Down's syndrome screened by a first trimester test, and $(C)$ proportion of continuing pregnancies that proceed to a second trimester test (all values are per 100000 pregnancies)

the patients in terms of travel and time off work, are not to be ignored.

It has been proposed that all women who screen negative at the first trimester will still require screening at the second trimester for neural tube defects ${ }^{8}$ and that this may affect the cost effectiveness of contingent screening. ${ }^{9}$ However, this is not applicable in our study since the standard practice in Canada and similar countries is that all women undergo a fetal ultrasound assessment at 20 weeks of gestation, ${ }^{50}$ so that a second trimester test for serum $\alpha$ fetoprotein seems to be unnecessary. ${ }^{5}$

\section{Sequential screening}

In accordance with reported data, ${ }^{69}$ we found sequential screening to be outperformed by contingent screening. This is probably due to the high proportion of women who proceed to a second trimester test under the sequential screening scenario. However, the contingent and sequential screening options are very similar with regard to other outcomes.

\section{Integrated test}

Our results confirm reports that the integrated test results in few procedure related euploid miscarriages ${ }^{9}$ and that its principal advantage is the low number of unnecessary terminations (because this screening option allows a diagnostic test only in the second trimester). However, the integrated test does not allow identification of affected pregnancies at the first trimester, nor reassurance for women with unaffected pregnancies. This could be a disadvantage given that women seem to want an early diagnosis. ${ }^{3839}$

\section{Triple test}

Considering cost effectiveness and outcomes, triple test has too many limitations to be maintained as a desirable Down's syndrome screening strategy. But a screening option that starts in second trimester should also be available because one third of women seek prenatal care after the first trimester. ${ }^{7}$

\section{Amniocentesis for women aged $\geq 35$ years}

We show here that scheduling an amniocentesis for women aged $\geq 35$ years is not a cost effective strategy and should be abandoned rapidly. Also, this approach may produce seven times more procedure related euploid miscarriages than contingent screening.

\section{What screening option?}

We conclude that, depending on local conditions, ${ }^{16}$ contingent screening is the preferred screening strategy for Down's syndrome with a first trimester cut-off value for risk of 1 in 9. Obviously, if it becomes possible to perform non-invasive prenatal diagnosis of Down's syndrome by means of fetal DNA or cells in maternal blood new cost effectiveness studies will be needed. ${ }^{125354}$

Contributors: JG was principal investigator and was responsible for the study design and coordination, analysis of data, and drafting the manuscript. DR, GG, and DD made the computer simulations of screening

\section{WHAT IS ALREADY KNOWN ON THIS TOPIC}

Prenatal screening for Down's syndrome is widely used, with many different screening strategies but still no consensus on the most cost effective approach

New strategies that provide a relatively high detection rate combine tests at both first and second trimesters

\section{WHAT THIS STUDY ADDS}

For strategies that combine first and second trimester tests, the choice of cut-off value for risk in the first trimester test significantly influences the cost effectiveness ratios and outcomes

Contingent screening, with a first trimester cut-off value for high risk of 1 in 9, is the preferred option. This cut-off value is much higher than those generally used in screening programmes 
procedures and contributed to the data analysis and drafting the manuscript. EB validated the clinical design of the study and contributed to drafting the manuscript. JF and FR were responsible for analysis of pregnancies' characteristics and screening options applicable in Québec and interpretation of results and contributed to drafting the manuscript. JG is the guarantor for the study.

Funding: This study was funded by the CanGèneTest research consortium on genetic laboratory services through a team grant from the Institute of Genetics of the Canadian Institutes for Health Research, the Heart and Stroke Foundation of Canada, the Canadian Agency for Drugs and Technologies in Health, and the Canadian Genetics Diseases Network of Centres of Excellence. EB holds a clinician-scientist award from the Canadian Institute for Health Research and the Jeanne et Jean-Louis Lévesque Perinatal Research Chair at Laval University. Competing interests: None declared.

1 Wald NJ, Watt HC, Hackshaw AK. Integrated screening for Down's syndrome on the basis of tests performed during the first and second trimesters. N Engl / Med 1999;341:461-7.

2 Wapner R, Thom E, Simpson JL, Pergament E, Silver R, Filkins K, et al. First-trimester screening for trisomies 21 and 18. N Engl J Med 2003;349:1405-13.

3 Roizen NJ, Patterson D. Down's syndrome. Lancet 2003;361:1281-9.

4 Resta RG. Changing demographics of advanced maternal age (AMA) and the impact on the predicted incidence of Down syndrome in the United States: implications for prenatal screening and genetic counseling. Am J Med Genet A 2005;133:31-6.

5 Wyatt $P$. Integrated, sequential, and contingent screening for Down syndrome-local needs should drive methodology. Prenat Diagn 2007;27:186-7.

6 Ball RH, Caughey AB, Malone FD, Nyberg DA, Comstock CH, Saade GR, et al. First- and second-trimester evaluation of risk for Down syndrome. Obstet Gynecol 2007;110:10-7.

7 Reddy UM, Wapner RJ. Comparison of first and second trimester aneuploidy risk assessment. Clin Obstet Gynecol 2007;50:442-53.

8 Reddy UM. The evolving prenatal screening scene. Obstet Gynecol 2007;110:2-4

9 Wald NJ, Rudnicka AR, Bestwick JP. Sequential and contingent prenatal screening for Down syndrome. Prenat Diagn 2006;26:769-77.

10 Platt LD, Greene N, Johnson A, Zachary J, Thom E, Krantz D, et al. Sequential pathways of testing after first-trimester screening for trisomy 21. Obstet Gynecol 2004;104:661-6.

11 Benn P, Wright D, Cuckle H. Practical strategies in contingent sequential screening for Down syndrome. Prenat Diagn 2005;25:645-52.

12 Malone FD, Canick JA, Ball RH, Nyberg DA, Comstock CH, Bukowski R, et al. First-trimester or second-trimester screening, or both, for Down's syndrome. N Engl J Med 2005;353:2001-11.

13 Wald NJ, Rodeck C, Hackshaw AK, Walters J, Chitty L, Mackinson AM. First and second trimester antenatal screening for Down's syndrome: the results of the Serum, Urine and Ultrasound Screening Study (SURUSS). J Med Screen 2003;10:56-104.

14 Palomaki GE, Steinort K, Knight GJ, Haddow JE. Comparing three screening strategies for combining first- and second-trimester Down syndrome markers. Obstet Gynecol 2006;107(2 Pt 1):367-75.

15 Kotaska A. Prenatal screening for fetal aneuploidy. J Obstet Gynaecol Can 2007;29:499-500.

16 Summers AM, Langlois S, Wyatt P, Wilson RD. Prenatal screening for fetal aneuploidy. J Obstet Gynaecol Can 2007;29:146-79.

17 Caughey AB. Cost-effectiveness analysis of prenatal diagnosis: methodological issues and concerns. Gynecol Obstet Invest 2005;60:11-8

18 BiggioJR Jr, Morris TC, Owen J, Stringer JS. An outcomes analysis of five prenatal screening strategies for trisomy 21 in women younger than 35 years. Am J Obstet Gynecol 2004;190:721-9.

19 Boulware LE. Challenges for public campaigns to improve the health of persons at high risk of developing CKD. Am J Kidney Dis 2008;51:535-8.

20 Antenatal diagnosis. Report of a consensus development conference. Bethesda, MD: National Institutes of Health, 1979. (NIH Publication No 79-1973.)

21 Haute Autorité de Santé. Évaluation des stratégies de dépistage de la trisomie 21. Recommandation en santé publique Juin 2007.www. has-sante.fr/portail/upload/docs/application/pdf/ synthese_evaluation_des_strategies_de_depistage_de_la_triso mie_21.pdf.

22 AETMIS. Le dépistage prénatal du syndrome de Down et d'autres aneuploides au premier trimestre de la grossesse. 2003. (AETMIS 03 01) xxi:84. www.aetmis.gouv.qc.ca/site/416.262.0.01.0.phtm

23 MSSS. Recensement de 2001. Institut de la Statistique du Québec, 2007. www.stat.gouv.qc.ca
24 Morris JK, Mutton DE, Alberman E. Revised estimates of the maternal age specific live birth prevalence of Down's syndrome. J Med Screen 2002;9:2-6.

25 Morris J, Mutton D, Alberman E. Corrections to maternal age-specific live birth prevalence of Down's syndrome.JMed Screen 2005;12:202.

26 Snijders RJ, Sundberg K, Holzgreve W, Henry G, Nicolaides KH. Maternal age- and gestation-specific risk for trisomy 21. Ultrasound Obstet Gynecol 1999;13:167-70.

27 Snijders R. Fetal loss in Down syndrome pregnancies. Prenat Diagn 1999;19:1180.

28 Forest J-C, Blouin D, Cartier L, Désilets V, Framarin A, Lemyre E, et al. Rapport du comité d'experts sur le dépistage prénatal du syndrome de Down et autres aneuploîdies. Québec: CHUQ-CHUL, AÉTMIS, MSSS, CHUS, CUSM, 2004

29 MSSS. Banque de données APR-DRG (All Patient Refined Diagnosis Related Groups): Ministère de la Santé et des Services Sociaux du Québec, 2003.

30 MSSS. SIFO Système d'Information Financière et Opérationnelle: méthodologie. Quebec: Direction de la gestion de l'information, Ministère de la Santé et des Services Sociaux (MSSS), 2005.

31 MSSS. Laboratoire de biologie médicale, Mesure de la production Edition 2006-2007. Quebec: La Direction des communications, Ministère de la Santé et des Services Sociaux (MSSS), 2007.

32 RAMQ. Manuel des médecins spécialistes. Quebec: Régie de l'assurance maladie du Québec (RAMO), Direction des services à la clientèle professionnelle, 2005:607.

33 RAMQ. Manuel des médecins spécialistes de laboratoires en établissement. Quebec: Régie de l'assurance maladie du Québec (RAMQ), Direction des services à la clientèle professionnelle, 2007:176.

34 Drummond MF, Sculpher MI, Torrance GW, O’Brien BJ, Stoddart GL. Methods for the economic evaluation of health care programmes. $3 \mathrm{rd}$ ed. Oxford: Oxford University Press, 2005:1-396.

35 Hoover SV, Perry RF. Simulation: a problem-solving approach. London: Addison Wesley, 1989.

36 Bishop AJ, Marteau TM, Armstrong D, Chitty LS, Longworth L, Buxton MJ, et al. Women and health care professionals' preferences for Down's syndrome screening tests: a conjoint analysis study. BJOG 2004;111:775-9.

37 Carroll JC, Reid AJ, Woodward CA, Permaul-Woods JA, Domb S, Ryan G, et al. Ontario Maternal Serum Screening Program: practices, knowledge and opinions of health care providers. CMA) 1997;156:775-84

38 Mulvey S, Zachariah R, Mcllwaine K, Wallace EM. Do women prefer to have screening tests for Down syndrome that have the lowest screenpositive rate or the highest detection rate? Prenat Diagn 2003;23:828-32.

39 Spencer K, Aitken D. Factors affecting women's preference for type of prenatal screening test for chromosomal anomalies. Ultrasound Obstet Gynecol 2004;24:735-9.

40 Asch A. Prenatal diagnosis and selective abortion: a challenge to practice and policy. Am J Public Health 1999;89:1649-57.

41 Kuppermann M, Feeny D, Gates E, Posner SF, Blumberg B, Washington AE. Preferences of women facing a prenatal diagnostic choice: long-term outcomes matter most. Prenat Diagn 1999;19:711-6

42 Kuppermann M, Goldberg JD, Nease RFJr, Washington AE. Who should be offered prenatal diagnosis? The 35-year-old question. Am J Public Health 1999;89:160-3.

43 Cuckle HS. Effect of maternal age curve on the predicted detection rate in maternal serum screening for Down syndrome. Prenat Diagn 1998;18:1127-30.

44 Harris RA, Washington AE, Nease RF Ir, Kuppermann M. Cost utility of prenatal diagnosis and the risk-based threshold. Lancet 2004;363:276-82.

45 Petrou S, Mugford M. Should prenatal diagnostic testing be offered to all pregnant women on economic grounds? Lancet 2004;363:258-9.

46 Caughey AB, Kuppermann M, Norton ME, Washington AE. Nucha translucency and first trimester biochemical markers for down syndrome screening: a cost-effectiveness analysis. Am J Obstet Gynecol 2002;187:1239-45.

47 Chen Y, Qian X, Li J, Zhang J, Chu A, Schweitzer SO. Cost-effectiveness analysis of prenatal diagnosis intervention for Down's syndrome in China. Int J Technol Assess Health Care 2007;23:138-45.

48 Ritchie K, Bradbury I, Slattery J, Wright D, Iqbal K, Penney G. Economic modelling of antenatal screening and ultrasound scanning programmes for identification of fetal abnormalities. BJOG 2005;112:866-74

49 Egan JF, Kaminsky LM, DeRoche ME, Barsoom MJ, Borgida AF, Benn PA. Antenatal Down syndrome screening in the United States in 2001: a survey of maternal-fetal medicine specialists. Am J Obstet Gynecol 2002;187:1230-4.

50 Scott A. Nuchal translucency measurement in first trimester Down syndrome screening. Issues Emerg Health Technol 2007;(100):1-6. 
51 American College of Obstetricians and Gynecologists. First-trimester screening for fetal aneuploidy: opinion 296. Obstet Gynecol 2004;104:215-7.

52 Gekas J, Gondry J, Mazur S, Cesbron P, Thepot F. Informed consent to serum screening for Down syndrome: are women given adequate information? Prenat Diagn 1999;19:1-7.

53 Lau TK, Leung TN. Genetic screening and diagnosis. Curr Opin Obstet Gynecol 2005;17:163-9.

54 Jackson L. Fetal cells and DNA in maternal blood. Prenat Diagn 2003;23:837-46.
55 Morris JK, Wald NJ, Watt HC. Fetal loss in Down syndrome pregnancies. Prenat Diagn 1999;19:142-5.

56 Sundberg K, Bang J, Smidt-Jensen S, Brocks V, Lundsteen C, Parner J, et al. Randomised study of risk of fetal loss related to early amniocentesis versus chorionic villus sampling. Lancet 1997;350:697-703.

57 CETS. Les enjeux du dépistage et du diagnostic prénatals du syndrome de Down. 1999;(CETS 99-4 RF) xviii:92.

Accepted: 12 December 2008 